\title{
Developing El Niño could be strongest on record
}

\section{Event could bring rain to drought-stricken California and dry conditions to Australia.}

\section{Chris Cesare}

14 August 2015 I Corrected: 14 August 2015

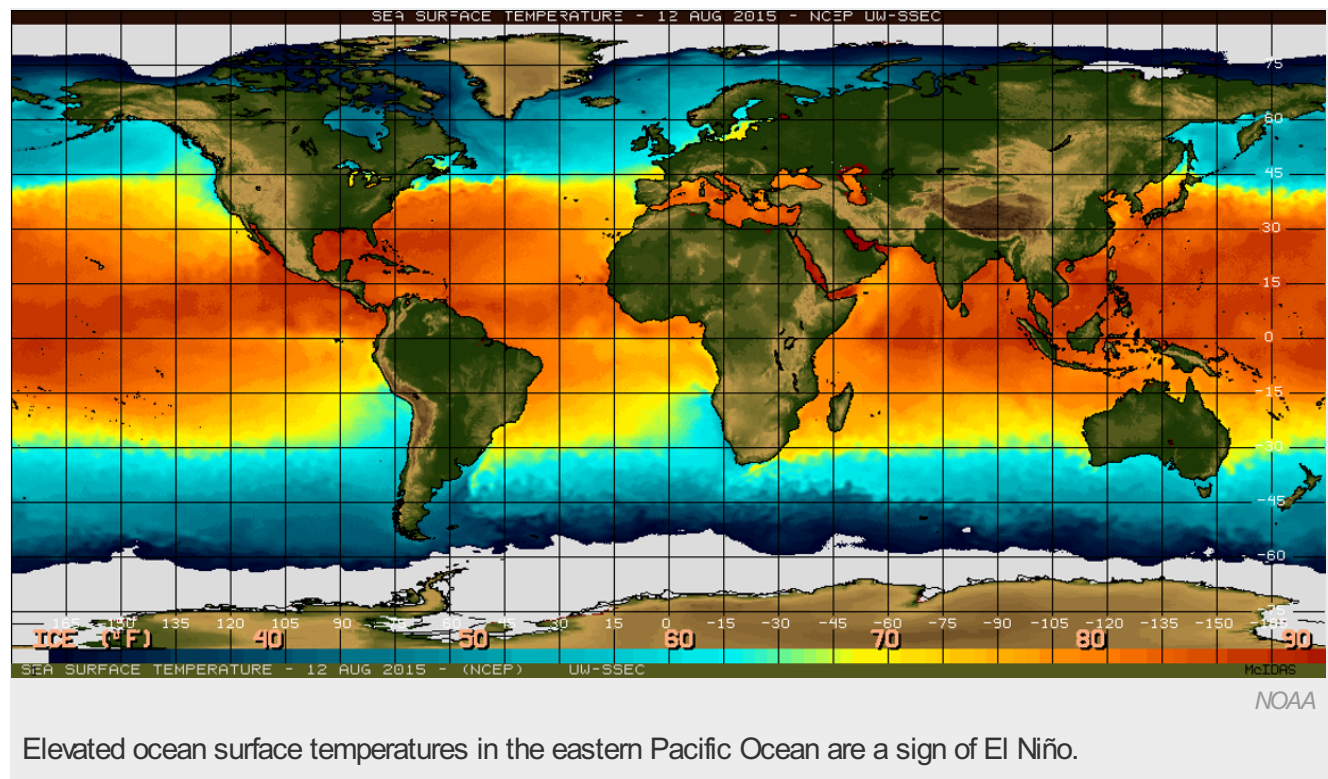

The El Niño weather pattern developing in the Pacific Ocean could eventually rank among the strongest on record, forecasters with the US National Oceanic and Atmospheric Administration (NOAA) said on 13 August.

A strong El Niño — signalled by the periodic warming of ocean-surface temperatures in the equatorial Pacific — can lead to heavy rain in parts of North America and drier-than-normal conditions in Australia, Indonesia and parts of India. NOAA says that there is an $85 \%$ chance that the current El Niño will last through the first few months of next year, with its strength peaking in November or December.

Nature explains why this El Niño is unusual, and how it might affect weather around the world.

\section{How does an El Niño form?}

The weather pattern is the product of a complex dance between sea-surface temperatures and atmospheric conditions.

Normally, trade winds from the east drive cold water from the depths of the eastern Pacific Ocean to the surface. But sometimes those winds weaken, causing the ocean surface to warm and heat the air above it. That warm air rises, and moves north and south from the equator - altering the high-altitude air currents along which storms tend to travel.

\section{How do scientists forecast an El Niño?}

Forecasters in the United States, Japan and Australia monitor sea-surface temperatures in the Pacific, paying particular attention to a region called Niño 3.4 in the eastern equatorial Pacific. They also track water temperatures below the ocean surface and the air pressure above, then feed this information into forecast models.

If ocean-surface temperatures in the Niño-3.4 region are between 0.5 to $1{ }^{\circ} \mathrm{C}$ above average during a three-month window, NOAA declares a weak El Niño. Forecasters label an El Niño as strong if it exceeds the average by $1.5^{\circ} \mathrm{C}$. NOAA projects that the current event could produce temperatures that are $2^{\circ} \mathrm{C}$ higher than average, or more.

For comparison, the strongest El Niño on record occurred in 1997-98 and produced temperatures $2.3^{\circ} \mathrm{C}$ above average.

\section{What makes this El Niño different?}

Two things. It started unusually early — in March instead of June. This could be because warm waters left over from last year's weak El 
Niño gave it a head start, says Anthony Barnston, chief forecaster at the International Research Institute for Climate and Society at Columbia University in Palisades, New York.

And this would be the second El Niño year in a row, following the weak El Niño that developed late last year, Barnston adds. A similar El Niño double-header happened between 1986 and 1988, but forecasters predict that the current El Niño will become stronger than either of those two events.

\section{Could this end the drought in California?}

El Niño could offer some relief to the US state, which is now in the fourth year of a historic drought. Forecasters say that there is a good chance that southern California will receive more rainfall than usual throughout the winter. In the past, very strong El Niños have also soaked the central and northern parts of the state.

Still, "one season of above-normal rain and snow is very unlikely to erase four years of drought", says Mike Halpert, deputy director of NOAA's Climate Prediction Center in College Park, Maryland. According to a study published last month in the Journal of Geophysical Research: Atmospheres ${ }^{1}$, California's rain shortfall since the start of the current drought is roughly equal to the amount of rain the state would receive in a normal year.

\section{What effects might El Niño have else where?}

El Niño is associated with higher atmospheric pressure in the western Pacific, which tends to produce sunny, dry weather in parts of Australia and Indonesia, says Barnston. The effects can spread all the way to India, which has experienced a relatively dry June and July. "They're having a bad monsoon in India," Barnston says.

In Peru, where waters off the coast typically warm during El Niño, the government has declared a state of emergency because of concerns about heavy rain and mudslides.

Nature | doi:10.1038/nature.2015.18184

\section{Corrections}

Corrected:This story originally stated that trade winds normally blow into the eastern Pacific Ocean from the west; these winds blow from the east. This has now been corrected.

\section{References}

1. Savtchenko, A. K., Hoffman, G. \& Vollmer, B. J. Geophys. Res. Atmos. http://dx.doi.org/10.1002/2015JD023573 (2015). 